\title{
VEINTICINCO AÑOS DE LAS ADMINISTRACIONES PÚBLICAS EN EL ESTADO CONSTITUCIONAL
}

\author{
JUAN FERNANDO LÓPEZ AGUILAR
}

Catedrático de Derecho Constitucional de la Universidad de Las Palmas de Gran Canaria y Catedrático Jean Monnet de Derecho Europeo 


\section{SUMARIO}

1. La eVolución de las Administraciones Públicas en 25 años de democraCIA CONSTITUCIONAL: DESCENTRALIZACIÓN TERRITORIAL E INTEGRACIÓN EUROPEA. 2. El futuro de las administraciones Públicas. 3. Conclusiones. IV. Un APUNTE BIBLIOGRÁFICO. 


\title{
VEINTICINCO AÑOS DE LAS ADMINISTRACIONES PÚBLICAS EN EL ESTADO CONSTITUCIONAL
}

\author{
POR \\ JUAN FERNANDO LÓPEZ AGUILAR
}

Catedrático de Derecho Constitucional de la Universidad de Las Palmas de Gran Canaria y Catedrático Jean Monnet de Derecho Europeo

1. LA EVOLUCIÓN DE LAS ADMINISTRACIONES PÚBLICAS EN 25 AÑOS DE DEMOCRACIA CONSTITUCIONAL: DESCENTRALIZACIÓN TERRITORIAL E INTEGRACIÓN EN EUROPA

Los valores de libertad, igualdad, justicia y pluralismo fueron proclamados en la Constitución de 1978 como fórmula de ordenación de la convivencia en el Estado social y democrático de Derecho; se proyectan, así pues, tanto en la definición de nuestro espacio común, como en el diseño normativo de nuestra misión de futuro. 25 años después, sigue siendo evidente que, para que estos valores democráticos puedan ser esgrimidos en calidad de algo más que meros referentes éticos, y puedan hacerse tangibles en la realidad cotidiana de la vida ciudadana, se requería, y se requiere, el compromiso activo y permanente de los poderes públicos, de las instituciones y de la ciudadanía. Estos mismos principios deben guiar y enmarcar las políticas y la actuación de los poderes públicos en la sociedad que queremos, en horizonte de futuro. 
Es por ello que la existencia y buen funcionamiento de las instituciones políticas, económicas y sociales, y dentro de ellas, de las Administraciones Públicas, constituyen instrumentos simplemente decisivos para que la sociedad sea más justa, disfrute de la igualdad esencial que sustenta el compromiso básico de toda ciudadanía y exprese su voluntad de solidaridad de manera eficaz y constante (art. 9.3 y $103 \mathrm{CE}$ ). Sin unas Administraciones Públicas (AA.PP.) éticamente comprometidas con los valores democráticos en su acción y actuación pública, sin unas AA.PP. eficaces, eficientes, responsables y próximas a los ciudadanos a los que se deben, el proyecto constitucional que arrancó hace 25 años no puede aspirar a plasmarse en realidades efectivas.

Ahora bien, si en el plano de los principios configuradores en el diseño constitucional de las AA.PP. parecía claro, en el plano de la práctica y la experiencia constitucional de las administraciones públicas se ha podido constatar una evidente evolución, y ello aunque sólo fuera porque en estos años se ha producido una maximización del principio dispositivo y de la potestad "auto-organizadora" de las CC.AA. (art. 148.1.1 (CE) que ha obrado el florecimiento en el paisaje autonómico de nuevas y diferentes manifestaciones de la denominada "cultura social estatistan, expresión de la confianza de los ciudadanos, creciente en estos años en España, en el valor de las administraciones como agentes del Estado social, especialmente respecto a la dimensión prestacional del Estado.

Las CC.AA. se han constituido, por tanto, como genuinos «subsistemas jurídico-públicos" completos, que han permitido la coexistencia de administraciones de base institucional (organismos públicos) y/o corporativa (colegios, cámaras, universidades), al tiempo que se multiplicaban los órganos auxiliares, consultivos o de control externo (Defensores del pueblo, Consejos consultivos, Audiencias de cuentas, Consejos económicos-sociales, Consejos de relaciones laborales, etc).

Así, de la Administración diseñada por la Constitución, regida por los principios de racionalidad, eficiencia y eficacia, a la verdadera Administración finalmente constituida, media algún trecho. Entre las razones de esta divergencia encontramos algunas muestras del mimetismo y de la desconfianza, que en relación con las Administraciones Públicas fueron descriptivas de la construcción del Estado de las Autonomías. Nuestro peculiar "autonomismo competitivo", expresión de la apuesta por un Estado compuesto de carácter no homogéneo, y en ocasiones recorrido de tensiones conflictuales y reivindicativas de sesgo bilateral, dio en llamar a este fenómeno la «dinámica de liebres 
y tortugas". Tanto fue así que uno, si no el más relevante, de los defectos achacados a la experiencia autonómica fue precisamente el de que, aparentemente, las Comunidades Autónomas habían acarreado, entre otros costes, el de multiplicar las instancias públicas de decisión e influencia, de burocracias y cargas, de sujeciones procedimentales y cauces institucionales.

Transcurridos 25 años, parece hoy un trabajo inútil el intentar detraer del Pacto constituyente la difusa frontera entre aquello que debia ser incorporado por todas las Comunidades $y$ aquello que por su naturaleza o su presupuesto fáctico debía distinguir a unas de otras. Sin embargo, tras la consolidación de un modelo de distribución competencial que ha tenido mucho de evolutivo y un fuerte componente convencional o pactado, la percepción de que este modelo compuesto de Administración pública ha mejorado la resolución de las demandas elementales de los ciudadanos ha sido cada día más consistente. Ello hace aún más visible la vigencia del principio de mayor eficacia en la prestación de los servicios públicos, mejora la calidad de dichos servicios, mediante la cercanía de las Administraciones Públicas al administrado.

En cuanto al modelo y a los condicionantes constitucionales impuestos para encauzar la actuación de las Administraciones Públicas, la Constitución apostó por un modelo políticamente neutro de Administración al servicio de los intereses generales. En este contexto, resulta destacable la innegable complejidad y diversidad caracterizante del cuadro total de las Administraciones Públicas operativas en el suelo español, que sin lugar a dudas obedece más a una inercia «preconstitucional» que a la específica política postconstitucional eventualmente adoptada por los poderes autonómicos emergidos a raíz de la actuación de las nuevas garantías constitucionales.

Este fenómeno puede ser explicado, al menos parcialmente, en función de la jurisprudencia constitucional. El decisivo protagonismo delTC en el desarrollo del Estado autonómico, para el que Manuel Aragón acuñaría la elocuente expresión "Estado jurisprudencial autonómico", se ha visto reflejado claramente también en este aspecto. Tanto activismo jurisprudencial ha tenido mucho que ver con la inicialmente evitable falta de previsión de las necesarias y adecuadas técnicas de auxilio, cooperación y colaboración entre administraciones $y$ entre diferentes escalones político-administrativos, condicionada, empero tanto por la Constitución como por el llamado bloque de constitucionalidad. Así aparece, por ejemplo, en el juego entre leyes de base/desarrollo en la distribución competencial en la construcción del 
régimen jurídico-institucional de las Administraciones Públicas en el Estado Autonómico. Sin la intervención delTC no habría sido posible la legitimación de la operación de "profunda reestructuración» en la configuración del conglomerado orgánico-administrativo sirviente hoy día a los poderes públicos

En cualquier caso, no es posible perder de vista a qué fines sirve la Administración y qué es lo que justifica la existencia de todo este aparato, constitucionalmente enderezado al uservicio de los intereses generales» (art. 103 y $106 \mathrm{CE}$ ): La repuesta eficaz al servicio público al que se debe es el único valor justificativo para iniciar cualquier tipo de reestructuración de las Administraciones públicas en el Estado Social y democrático de Derecho. Es en este plano en el que es posible plantearse qué separa la actividad que podemos llamar propiamente "administrativa" de la que es propiamente gubernamental por parte de la Administración del Estado. La legislación más reciente se encarga de este punto: LRJyPAC 30/1992; LOFAGE 1997; Ley del Gobierno, y el todavía pendiente nuevo Estatuto de la Función Pública.

En otro orden de cosas, la Constitución, además, renovó potentemente nuestra tradición iuspublicista, eminentemente administrativista: así, en lo referente a la distinción entre discrecionalidad y arbitrariedad, en asociación con el problema de control constitucional de la desviación de poder y de la sujeción de la actuación de las AA.PP. a los fines que la justifican (art. $106 \mathrm{CE}$ ). De este modo, la Ley constriñe a todos los poderes públicos al servicio de unos fines constitucional y legalmente predeterminados (art. $9 \mathrm{CE}$ ).

En estos 25 años han sido múltiples los terrenos en los que esta discusión sobre los contornos legales y constitucionales de la interdicción de la arbitrariedad de los poderes públicos viene desenvolviéndose y traduciéndose en la práctica. Tal es el caso, por ejemplo, de la configuración del control contencioso de la actuación de la administración y la recepción del control de constitucionalidad de la actuación por la vía de la Justicia Constitucional concentrada; o la "guerra de las Cortes"; el de la reconsideración de los llamados reglamentos independientes (derivación del alcance de la vinculación al principio de legalidad desde la Constitución, a la luz del art. $97 \mathrm{CE}$ ); o el de la idea clásica del «acto político» en régimen constitucional.

La necesidad de este control jurisdiccional de la actuación de los poderes públicos dimana de la doble función constitucional distintiva de las administraciones públicas, cual es precisamente el servicio al interés general, y de la propia función constitucional de gobierno como "acción de dirigir e impulsar políticamente al Estado". La cuestión es 
clásica y actual en nuestro Derecho Público: Se trataria, nada menos que de discernir positivamente lo que hay de político y lo que hay de administrativo en la actuación material de los poderes públicos. Estamos hablando, pues, de la naturaleza "política» de determinadas actuaciones de los poderes públicos que no afecta sólo al ámbito territorial de la Administración General del Estado y del Gobierno de la Nación, que no se restringe a las "materias clasificadas" a los "secretos de Estado", sino que alcanza a los actos denominados de planificación, los negociales, los técnicos y los de dirección o de relación entre órganos constitucionales del Estado. Y esta delimitación sigue siendo necesaria no sólo para el control del sometimiento de la Administración General del Estado a la Ley, sino también para la consagración y garantía de un propio ámbito distintivo de competencias de las administraciones públicas autonómicas, y en algunos casos de las corporaciones locales, que pueden siempre disponer de actuaciones que por su naturaleza son esencialmente políticas.

\section{EL FUTURO DE LAS ADMINISTRACIONES PÚBLICAS}

Tras veinticinco años de desarrollo constitucional, el balance del funcionamiento de las Administraciones Públicas puede ser considerado, como en el caso del resto de las instituciones, globalmente positivo, aun cuando sean constatables importantes claroscuros que afectan especialmente al último periodo del desarrollo del Estado Autonómico. Para empezar, es positivo porque, efectivamente, las Administraciones Públicas se han convertido en instrumentos esenciales al servicio de la construcción y consolidación de un verdadero espacio para la ciudadanía, y no son obviadas en la configuración de un programa o de una práctica política comprometida con la ciudadanía. Por su parte, los aspectos negativos pueden ser detectados a partir de algunas disfunciones que se han puesto de manifiesto al hilo de algunos de los problemas yà indicados.

Así, la organización de la Administración General del Estado es ineficiente porque su funcionamiento interno no resulta adecuado para las nuevas funciones de coordinación, regulación básica, defensa de los intereses de España en el exterior y Alta Inspección que la Constitución atribuye.Y las Administraciones Autonómicas lo son porque han reproducido demasiado miméticamente la vieja organización de la Administración del Estado y con ello sus problemas.

Pues bien, en este preciso momento en el que hacemos balance de los últimos 25 años de democracia, y a la luz de las demandas 
de una ciudadanía más activa, más y mejor informada, podemos decir que vivimos un proceso de revisión y de reconsideración en la relación de los administrados con las Administraciones Públicas.

De acuerdo con los registros demoscópicos al uso, se acusa a estas, insistentemente, de desconocer las necesidades $y$ expectativas de los ciudadanos en sus iniciativas de reorganización administrativa. La ciudadanía siente que la actuación de las Administraciones no siempre les facilita la vida, antes bien, en ocasiones parece incluso complicársela aún más poniendo innecesarias trabas a su iniciativa y creatividad. Creen que, en muchas ocasiones, su contribución fiscal se despilfarra y tienen dificultades para ejercer los derechos que les reconocen las leyes en sus relaciones con la Administración. Parece evidente, asimismo, que las nuevas tecnologías no han sido aprovechadas suficientemente para reducir la burocracia; y que los procedimientos no se orientan a la satisfacción de la ciudadanía, sino al cumplimiento de las formalidades legales. Además, los instrumentos de cooperación interadministrativa para la tramitación conjunta de sus iniciativas, resultan poco eficaces cuando las competencias se encuentran compartidas.

La modernización de las Administraciones Públicas se sitúa así, 25 años después de la Constitución, en el plano de mayor actualidad $y$ en el frontispicio de las propuestas electorales de los partidos mayoritarios. Así lo fue en las convocatorias del 96 y del 2000, y así lo será previsiblemente en la del 2004. El objetivo proclamado sigue siendo convertirlas en el instrumento transformador al que están constitucionalmente llamadas (art. 9.2 CE), frente a los poderes opacos, a los poderes fácticos y a los poderes privados, para servir más y mejor a la ciudadanía, para remover los obstáculos que impidan o dificulten el pleno disfrute de la libertad y la igualdad en las que se fundamenta nuestro orden de convivencia.

En este proceso de revisión para la modernización nos encontramos en los últimos años embarcados, desde la política y la doctrina, en una viva discusión, permanentemente abierta, a propósito de las diferentes opciones de reforma, tendentes en todo caso a la racionalización de las Administraciones públicas y su acercamiento al ciudadano, a partir de la simplificación y abaratamiento de los procedimientos, y de la modernización en la gestión de los recursos y del funcionariado público.

Entre las que descuellan por su particular relieve, merece reseña la que pivota desde hace años en lo que se ha denominado propuesta de "Administración única». Una versión conservadora de la 
misma propugna beligerantemente la progresiva reducción de lo público, con el alegado objetivo económico de la aseguración del sacralizado "deficit 0", por más que tal fetichismo imponga unos costes sociales regresivos o insoportables. Por dicha «administración única" se puede entender una de estas dos cosas: o bien la superación de nuestro actual modelo autonómico, que, como hemos descrito, ha devenido complejo, incluso heterogéneo y diverso -en determinados aspectos-, por otro modelo más próximo a lo que técnicamente se denomina "federalismo dual», es decir, por la construcción de líneas delimitadoras perfectas entre las atribuciones encomendadas a cada uno de los niveles políticos-administrativos; o bien, en segunda acepción, la simplificación de todas las administraciones públicas tendiendo a residenciar en las CC.AA. las competencias normalmente ejecutivas que no quepa conectar con la almendra o núcleo duro de la soberanía estatal, aproximándonos así al "federalismo cooperativo" alemán. En cualquiera de las dos interpretaciones posibles resultaría necesario, para alcanzar el objetivo apuntado, emprender reformas de calado que pasan por revisar fuertemente el listado de competencias exclusivas del Estado tal y como se encuentra contemplado en el art. 149.1 CE a la luz de la maximización de las potencialidades de transferencia y/o delegación de competencias estatales en beneficio de los poderes autonómicos según el art. 150.2 CE. En uno u otro caso, la percepción ciudadana de este planteamiento parece corresponderse más bien con la ejecución de una política de reducción de la administración pública en la oferta de servicios públicos, desde la imputación de que no resulta eficaz para dar satisfacción a nuevas preocupaciones de la sociedad; al revés, ha acarreado la aparición de graves problemas sociales, como son la creciente delincuencia, la desintegración y desestructuración de los tejidos y redes de solidaridad, el vandalismo, y nuevas formas de marginalidad social.

$Y$ sin embargo, lo cierto es que la insuficiencia de las inversiones, junto con la congelación indiscriminada de la oferta de empleo público de los últimos años, ha provocado un deterioro creciente de los servicios públicos, por lo que la parte más pudiente de la ciudadanía se ha visto invitada a acudir al sector privado en busca de la eficacia y los niveles de calidad que las Administraciones Públicas no han sido capaces de proporcionarles, asumiendo el coste adicional que supone la externalización de tantos e importantes servicios.

Miguel Sánchez Morón ha apuntado ya hace tiempo cómo la solución meramente normativa de cara al perfeccionamiento del régimen de coexistencia de varias AA.PP. sobre un mismo territorio debe ser acogida siempre con enormes reservas, siquiera porque actual- 
mente disponemos ya en vigor de numerosas competencias, así como de técnicas de coordinación o de reconducción a una mínima homogeneidad técnica o niveladora de competencias autonómicas, que sin embargo, no han sido, ni están siendo utilizadas. Aunque sólo sea por ello, se debe desconfiar de que éste sea el más efectivo vehículo transformador de la Administración Pública. Parece más operativo acudir a la práctica y ver cuáles son las soluciones que la realidad ha convalidado o que empíricamente han funcionado. Y en ello podemos apreciar un decisivo avance en las técnicas de auxilio, colaboración, encomienda de gestión, cooperación y coordinación que han hecho posibles tras 25 años de ejercicio, reducir la fuerte presencia del conflicto y las técnicas de conflictualidad en nuestro Estado compuesto. Así han actuado la Ley 14/1983 y la Ley 30/1992 que en su día formalizaron técnicas y cauces de colaboración e interrelación bilateral y multilateral que ninguna presencia expresa tenían ni podían tener en la Constitución. E incluso, como señala Adolfo Hernández, cabe afirmar que ha sido asi como se han abierto paso, por vía de prueba y error, cauces empíricos y pragmáticos hasta su institucionalización. Tal es el caso, por ejemplo, de los Convenios de colaboración, las encomiendas de gestión, los acuerdos de cooperación en Juntas bilaterales, los Consorcios, los acuerdos de la Conferencia sectorial y los Convenios de Conferencia Sectorial, que han venido a completar al hilo de la experiencia los cauces de colaboración y conflicto entre AA.PP. estatal y autonómicas con las Administraciones locales.

Frente a la ofensiva conservadora de erosión y desprestigio continuado de lo público, una propuesta progresista de modernización de las Administraciones Públicas pasa, antes bien, por vincularlas a los servicios públicos que ofrecen. Las Administraciones Públicas no son fines en sí mismas, como tampoco instrumentos al servicio del partido gobernante. Las Administraciones Públicas, son, y han de ser, instrumentos al servicio de la ciudadanía, de sus derechos y libertades. El objetivo político es y tiene que ser el de garantizar la transparencia y responsabilidad de los poderes públicos, la proximidad, la ética en la acción pública, la eficacia, la eficiencia y la responsabilidad de la Administración, para que sean un instrumento eficaz de bienestar, de cambio y progreso social al servicio de los ciudadanos.

Partiendo de dicha premisa, se proponen, por un lado, específicas reformas internas, con nuevas políticas salariales y de recursos humanos que incluyan programas a favor de la participación del empleado público y la dignificación del servicio público; y por otro lado, externas, con nuevas políticas en las que se garantice la audiencia y la participación de los ciudadanos en la administración, los meca- 
nismos de responsabilidad de los poderes públicos; estimulando la rendición de cuentas y fomentando la transparencia de la acción administrativa, para que todos los ciudadanos conozcan qué hacen, cómo y en qué se gastan su dinero, cómo gestionan hasta el último euro de los presupuestos, con quién, cuánto y para qué contratan, qué impactos producen sus políticas sobre la realidad y cuál es su proyecto estratégico. Sólo así podrán controlar efectivamente la acción del Gobierno $y$ aprobar o rechazar, en términos democráticos, sus políticas $y$ actos concretos.

Se propugnan, además, múltiples medidas directas, como una nueva oferta de servicios públicos; inversiones públicas sostenidas y no menguantes, control de los servicios externalizados, evaluación de la calidad de los servicios y cooperación entre administraciones. Junto a estas, otras de corte democrático como que la ciudadanía participe en el diseño de las políticas y servicios públicos, o la mayor implicación de los responsables políticos en la mejora de los servicios. Para reforzar la eficacia del Estado y asegurar la calidad de los servicios se pide que las Administraciones Públicas se comprometan más activamente en el desarrollo de los principios constitucionales de legalidad, justicia, libertad y solidaridad como criterios que han de orientar y dotar de legitimidad a la totalidad de la actuación administrativa.

Lo que, al menos en los discursos y en la retórica oficial, parece estar asumido por todos los actores políticos es la necesidad de introducir y potenciar el uso de las nuevas tecnologías en la Administración del S. XXI para elevar su rendimiento en el cumplimiento de sus funciones $y$ en la prestación del servicio público, con la finalidad última y el horizonte irrenunciable de que todo ello repercuta en un mejor servicio para los ciudadano

Dicho esto, es cada vez más evidente que el curso de los próximos años para las Administraciones Públicas pasa por una ascendente emergencia de la administración local, sin duda, la gran relegada de la experiencia constitucional descentralizadora a partir de la Constitución de 1978. Ahora nos hallamos, en efecto, en el momento idóneo para el perfeccionamiento del instrumentario jurídico-institucional que ha venido conociéndose como «Pacto local». Bajo la alocución "pacto local" se reconoce una suerte de convención constitucional cuyo objeto es asumir y promover, por parte de las principales fuerzas políticas y actores constitucionales partícipes del sistema, el protagonismo en éste de los poderes públicos locales, en diversidad de planos: institucional, competencial, financiero y prestacional. 
No obstante, en este fin también los métodos aparecen divergentes entre las diferentes opciones políticas. Así, mientras que unas propugnan la descentralización de poder autonómico en beneficio de un mayor protagonismo local, otras defienden una mayor participación de las CC.AA. en el proceso, toda vez que, en lo local, poco o nada podrá hacerse para optimizar, racionalizar, simplificar y potenciar el mejor rendimiento de las AA.PP. coexistentes, activando los dispositivos del Título VIII de la $\mathrm{CE}$, sin la participación decisiva, activa y protagonista de las CC.AA. y de sus poderes políticos dentro de su sustantivo ámbito de responsabilidad.

En todo caso, es patente que en el acometimiento y ejecución de este proceso ya no es sólo competente y responsable el Estado y sus poderes políticos. El Pacto local vincula una ofensiva en el frente de lo que se ha denominado "nuevo centralismo autonómico", haciendo que las CC.AA. actúen desde su cuota de participación en el reparto constitucional de competencias sobre las Administraciones locales. La proliferación de nuevos niveles administrativos, como ejemplificarían la comarcalización de Cataluña o en Castilla y León, no se ha visto acompañada del desapoderamiento de otros escalones locales protegidos, de acuerdo con la jurisprudencia del TC sobre la garantía institucional (STC 32/1981).

Ahora bien, con todo y con eso, sigue siendo preciso diferenciar con mejores trazos los regímenes jurídicos de los pequeños municipios de los de las grandes ciudades, en lo institucional, y, asi, en lo financiero, aunque la solución de las mancomunidades intermunicipales para la prestación de servicios comunes en municipios limítrofes, haya cubierto, hasta ahora, algunos importantes vacíos.

$Y$ para este objetivo es y será en el futuro imprescindible la interlocución y la cooperación multilateral institucionalizada en los foros institucionalizados para ello, canalizando la inserción de los diferentes niveles político-administrativos de ámbito subestatal (CC.AA. y entes locales), estatal y europeo (Conferencia intergubernamental 1996-1997), acompañándose, en fin, del debido debate social, doctrinal y político.

\section{CONCLUSIONES}

La Constitución española de 1978 diseñó, en definitiva, un régimen de prestación de amplios servicios públicos en el marco de un Estado social y democrático de Derecho, que simultáneamente debía 
acometer la reconversión desde el más férreo centralismo hacia el Estado compuesto, estructurando diversos poderes y administraciones. Los designios del constituyente español no han sido, con todo, plenamente cumplidos y en su desarrollo de estos 25 años inducen una evaluación con intensos claroscuros, aderezados por la difusamente negativa percepción ciudadana del rendimiento obtenido por la proliferación de diferentes niveles administrativos. Los ciudadanos de hoy critican la ineficiencia, la lentitud y el elevado coste de las nuevas Administraciones públicas en un balance insostenible en la era de las nuevas tecnologías.

En cierto modo, alguna explicación podemos encontrar en la irresponsabilidad financiera y en la llamada «ilusión fiscal" que ha caracterizado, fuertemente, al menos, la última década de construcción del Estado de las Autonomías, acaso más que en la falta de desarrollo legislativo o en la carencia de instrumentos de colaboración, que, como hemos visto, se han impuesto sin embargo en la experiencia y en la práctica.

Pero, a pesar de ello, no podemos olvidar que la Constitución que hoy celebramos propugna un Estado conformado por poderes públicos responsables, que no descarguen en la ciudadanía el peso de solucionar por sí mismos problemas que dada su envergadura y alcance, en modo alguno pueden ser abordados con eficacia desde la acción individual; un Estado social y democrático de Derecho que sea capaz de defender activamente los derechos y libertades de todos, de velar por la seguridad ciudadana y generar un entorno que favorezca la autonomía individual y la mejora de la calidad de vida de la gente, asi como la solidaridad y la cohesión social e interterritorial; que garantice la gestión directa de los servicios públicos esenciales; un funcionamiento equilibrado del mercado, que asegure la estabilidad económica y que impulse el progreso de la sociedad, desarrollando una red de infraestructuras y servicios públicos adecuada a las exigencias y al ritmo de la vida actual de los ciudadanos y ciudadanas.

Tras 25 años de Constitución está plenamente actualizado el debate doctrinal y político sobre la modernización, renovación y actualización de la Administración Pública, haciendo especial hincapié en la actualización del marco financiero y presupuestario a partir del cual las modernas AA.PP. podrán desarrollar las funciones constitucionales que tienen encomendadas.

$Y$ para ello, simplemente, ninguna reforma legislativa tiene la panacea. En el cambio de Siglo, nuestras Administraciones Públicas necesitan nuevos objetivos para asumir y dar servicio a las nuevas rela- 
ciones sociales. Las instituciones públicas, en su ámbito territorial y sus competencias, han de trabajar de otra forma, desde otras actitudes, e incluso desde otra mentalidad y otra ética pública altamente robustecida: comprometida, cooperante, interactiva y en red. Los gobiernos han de convertirse en organizaciones que escuchen a la ciudadania, que den soluciones tan democráticas como eficaces, implicándose activamente en la resolución de los problemas de la gente, y fomentando la participación ciudadana en la Administración, para la mejora de la calidad de los servicios que ésta presta.

Las Administraciones Públicas han de convertirse en organizaciones receptivas, flexibles y abiertas a la innovación; capaces de aprovechar, valerse y hacer valer las nuevas tecnologías y el conocimiento $y$ experiencia su personal, en beneficio siempre del interés general y en cumplimiento riguroso de la legalidad. Asegurando la excelencia de los servicios públicos para que den respuesta a las circunstancias cambiantes de la sociedad, que procuren el máximo bienestar individual y colectivo. Se trataría de ejecutar, a través de ellas, una nueva forma de hacer política desde el mejor y más eficaz funcionamiento de las Administraciones Públicas, focalizada en los ciudadanos y sus necesidades, destinada a potenciar una ciudadanía activa, innovadora y exigente.

Permítaseme concluir que cualquiera que sea la propuesta finalmente adoptada, la modernización de las Administraciones Públicas pasa por una revitalización de la importancia de lo público. Del Estado, por lo tanto, y de los poderes públicos, imponiéndoles la eficacia y la eficiencia, no sólo para la satisfacción individual de las pretensiones e intereses legítimos de cada ciudadano en su relación con la administración, sea cual sea su nivel (estatal, autonómica o local), sino también, y sobre todo, porque la calidad de los servicios públicos se halla nuclear y directamente relacionada con la calidad democrática que queremos para nuestra sociedad, y ello va inseparablemente unido a la necesidad de transparencia y responsabilidad en la gestión y garantía de los servicios públicos a los que se debe el Estado.

\section{UN APUNTE BIBLIOGRÁFICO}

ARAgón ReYes, Manuel, "¿Estado jurisprudencial autonómico?», RVAP, num. especial, Oñate (1987).

García Fernández, Javier, El Gobierno en acción, CEC, Madrid, 1996. 
García Morillo, Joaquín, La garantía constitucional de la administración local, Marcial Pons, Madrid (1997).

López AgUiLAR, Juan Fernando, "Las Administraciones públicas en el estado compuesto según la Constitución española de 1978», RFD UCM, . $^{\circ} 21$.

Rodríguez Arana, Jaime, La administración única, EGAP, Santiago (1995).

SÁNCHEZ MORÓN, Miguel, «Racionalización administrativa y organización territorial", $R E D C$, n. ${ }^{\circ} 40$ (1994).

VV.AA., Anuario de administración local, Fundación Pi-Sunyer, BarceIona (1995).

- El Funcionamiento del Estado autonómico, MAP, Madrid (1996).

- La provincia en el Estado Autonómico, Fundación Pi-Sunyer, Barcelona (1996). 